\title{
Soluble Urokinase Receptor Levels in Secondary Focal Segmental Glomerulosclerosis
}

\author{
Pingping Sun ${ }^{a-d}$ Lei Yu ${ }^{f}$ Jing Huang ${ }^{a-d}$ Suxia Wang ${ }^{a-e}$ Wanzhong Zou $^{a-d, g}$ \\ Li Yang $^{\mathrm{a}-\mathrm{d}}$ Gang Liu ${ }^{\mathrm{a}-\mathrm{d}}$
}

${ }^{a}$ Renal Division, Department of Medicine, Peking University First Hospital, Beijing, China; ${ }^{b}$ Key Laboratory of Renal Disease, Ministry of Health of China, Beijing, China; ' ${ }^{C}$ Key Laboratory of Chronic Kidney Disease Prevention and Treatment, Ministry of Education of China, Beijing, China; ${ }^{d}$ Renal Pathology Center, Institute of Nephrology, Peking University, Beijing, China; 'Laboratory of Electron Microscopy, Pathological Center, Peking University First Hospital, Beijing, China; ${ }^{f}$ Renal Division, Inner Mongolia People's Hospital, Hohhot, China; ${ }^{9}$ Department of Pathology, Peking University Health Science Center, Beijing, China

\section{Keywords}

Secondary focal segmental glomerulosclerosis . Soluble urokinase receptor - Alport's syndrome - Obesity-related focal segmental glomerulosclerosis - Diabetic nephropathy

\footnotetext{
Abstract

Background: Soluble urokinase receptor (suPAR) has been reported to be a possible permeability factor causing primary focal segmental glomerulosclerosis (FSGS) in recent years. We investigated the plasma and urinary suPAR levels in patients with 3 common types of secondary FSGS: Alport's syndrome (Alport-FSGS), obesity-related FSGS, and diabetic nephropathy. Methods: Fifty-two secondary FSGS patients diagnosed by kidney biopsy, including 8 with Alport-FSGS, 20 with obesity-related FSGS, and 24 with diabetic nephropathy, were enrolled in the study in the period from January 2008 to June 2014 at the Renal Division, Peking University First Hospital. Fifty-six healthy donors and 74 patients with primary FSGS, 14 with minimal-change disease, and 29 with
}

membranous nephropathy were used as healthy controls and disease controls, respectively. Plasma and urinary suPAR concentrations were measured with commercial ELISA kits, and their correlations with clinical and pathological data were analyzed. Results: Both plasma and urinary suPAR levels in the total secondary FSGS group were significantly higher than in healthy controls $(p<0.0001$ and $p<0.001$, respectively). There was no significant difference in levels of plasma and urinary suPAR in the Alport-FSGS, obesity-related FSGS, and diabetic nephropathy groups $(p=0.64$ and $p=$ 0.72 , respectively). The plasma suPAR level was not correlated with estimated glomerular filtration rate and urine protein. Conclusions: The levels of plasma and urinary suPAR in patients with Alport-FSGS, obesity-related FSGS, and diabetic nephropathy were increased. Plasma suPAR might be a pathogenetic participation factor or a useful marker of glomerular diseases with FSGS-associated podocytopathy but is not necessarily a circulating permeability factor.

(c) 2019 S. Karger AG, Basel

\section{KARGER}

(c) 2019 S. Karger AG, Basel 


\section{Introduction}

Focal segmental glomerulosclerosis (FSGS), manifesting with proteinuria, slowly progressive renal failure, and pathological lesions of focal and segmental glomerular sclerosis is associated with podocyte injury or podocytopathy $[1,2]$, but its etiology and pathogenesis have not been well elucidated. The view that some permeability factor may exist in primary FSGS patients has been proposed after extensive clinical observation [3-7].

After about 25 years of research via a series of elaborate in vitro and in vivo experiments, Wei et al. [8] identified soluble urokinase receptor (suPAR) as a circulating factor that may cause primary FSGS. Many confirmatory experiments followed, but the results were controversial. If suPAR is indeed the major circulating factor causing primary FSGS, the suPAR concentration in plasma may be different from secondary FSGS, i.e., that caused by other mechanisms such as increased intraglomerular pressure, viruses, drug toxicity, etc.

In our previous study, we measured plasma suPAR levels in 14 patients with secondary FSGS and found no differences between primary and secondary FSGS [9]. These patients were only pathologically diagnosed as having secondary FSGS: 1 with pre-eclampsia, 1 with Kimura disease, 2 with obesity, 2 with Alport's syndrome (Alport-FSGS), and 8 with unidentifiable disease. Due to these miscellaneous and ambiguous causes and the small number of patients, there may have been a bias in the results. In this study, we enrolled patients with the 3 mostcommon types of secondary FSGS or podocytopathy from obesity (glomerular hyperperfusion-induced podocyte injury), Alport-FSGS (glomerular basement membrane deficiency-induced podocyte injury), and diabetic nephropathy (podocytopathy induced by multiple mechanisms) to measure their plasma and urinary suPAR levels and analyze them along with clinicopathological data.

\section{Materials and Methods}

\section{Patients}

Fifty-two patients, including 8 with Alport-FSGS, 20 with obesity-related FSGS, and 24 with diabetic nephropathy, and diagnosed in the Peking University First Hospital from the 1st of January 2008 to the 30th of June 2014, were enrolled in this study. Patients with Alport-FSGS were enrolled when the following criteria were met: (a) abnormal staining of the COL IV a3-chain or a5chain in the glomerular basement membrane, (b) typical ultrastructural changes of Alport-FSGS observed under electron microscope [10], and (c) an FSGS lesion was observed under a light microscope. Obesity-related FSGS was defined as body mass index
(BMI) $\geq 28.0$, glomerular hypertrophy with FSGS lesions, and less diffuse foot process effacement visible by electron microscope [11]. The enrollment criteria for diabetic nephropathy were: (a) a history of diabetic mellitus $>5$ years, (b) nodular sclerosis and/or FSGS lesions observed under a light microscope, and (c) the exclusion of other glomerular diseases $[12,13]$. In this study, the term "secondary FSGS" refers to these 3 kinds of disease.

The clinical and pathological data were collected at the time of renal biopsy. Seventy-four patients with primary FSGS, 14 with minimal-change disease (MCD), and 29 with membranous nephropathy $(\mathrm{MN})$ were used as disease controls. According to Heptinstall's Pathology of the Kidney [14], the pathologic diagnosis of primary FSGS requires that focal glomeruli are involved and that one glomerulus shows segmental sclerosis, usually with tubular and interstitial injuries. Segmental lesions with a matrix and hyaline accumulation, endocapillary hypercellularity, and hyalinosis occur at the periphery of the glomerular tuft. Electron microscopy typically demonstrates diffuse effacement of podocyte foot processes in primary FSGS, but this is usually focal in secondary FSGS, as in our previous report [9]. Fifty-six healthy subjects were used as healthy controls.

\section{Renal Histopathology Assessment}

Renal biopsy specimens were examined by routine direct immunofluorescence, light microscopy, and electron microscopy. Two pathologists evaluated the biopsies separately. Differences in scoring by the pathologists were resolved by re-reviewing the biopsies to reach a consensus. The percentage of global sclerosis and the percentage of segmental or nodular sclerosis in glomeruli were recorded. Renal tubular atrophy and interstitial fibrosis were scored as the area involved: " 1 " for $<25 \%$ of the tubulointerstitial area and " 2 " for $\geq 25 \%$.

\section{Sample Collection and suPAR Measurements}

Plasma samples of patients using disodium-EDTA as an anticoagulant were collected on the day of renal biopsy. Spot urine samples of patients were collected at the same time. The plasma and urine samples, collected immediately after centrifugation at $2,000 \mathrm{rpm}$ for $15 \mathrm{~min}$ at $4{ }^{\circ} \mathrm{C}$, were stored at $-80^{\circ} \mathrm{C}$ in aliquots until use. Repeated freeze/thaw cycles were avoided.

We detected the concentration of plasma and urinary suPAR using the Quantikine Human uPAR Immunoassay (R\&D Systems, Minneapolis, MN, USA) following the manufacturer's protocol. In brief, the assay involved 5 steps: (1) 96-well polystyrene microplates were precoated with mouse monoclonal antibody against uPAR; (2) both plasma and urine samples were diluted 1:5 and added to each well and incubated for $2 \mathrm{~h}$ at room temperature; (3) after incubation and washing, horseradish peroxidase-conjugated polyclonal antibodies against uPAR were added and there was incubation for $2 \mathrm{~h}$ at room temperature; (4) after washing, substrate solution was added to each well and the contents were incubated for $30 \mathrm{~min}$ at room temperature, and protected from light; and (5) a stop solution was added to each well and absorbance was recorded using an enzyme-linked immunosorbent assay (ELISA) reader at $450 / 570 \mathrm{~nm}$. The suPAR level of each sample was calculated using Curve Expert software v1.3 (Chattanooga, TN, USA).

\section{Statistical Analysis}

Statistical analysis was performed with statistical software SPSS v19.0 (Chicago, IL, USA). Comparison of quantitative parameters was assessed using the nonparametric test between 2 nonnormally 
Table 1. The demographic and clinicopathological parameters of patients with secondary FSGS

\begin{tabular}{|c|c|c|c|c|c|}
\hline Characteristics & $\begin{array}{l}\text { All patients } \\
(n=52)\end{array}$ & $\begin{array}{l}\text { Alport-FSGS } \\
(n=8)\end{array}$ & $\begin{array}{l}\text { Obesity-related FSGS } \\
(n=20)\end{array}$ & $\begin{array}{l}\text { Diabetic nephropathy } \\
(n=24)\end{array}$ & $p$ value $^{\mathrm{a}}$ \\
\hline Age, years & $38.3 \pm 15.7$ & $18.5 \pm 5.0$ & $34.0 \pm 12.5$ & $48.5 \pm 12.2$ & 0.000 \\
\hline UTP, g/24 h & $4.2(2.5-5.9)$ & $3.5(2.0-4.7)$ & $2.9(2.0-5.7)$ & $5.0(3.9-8.2)$ & 0.007 \\
\hline $\mathrm{Alb}, \mathrm{g} / \mathrm{L}$ & $33.0 \pm 6.2$ & $30.8 \pm 4.1$ & $38.1 \pm 4.8$ & $29.4 \pm 4.7$ & 0.000 \\
\hline $\mathrm{Scr}, \mu \mathrm{mol} / \mathrm{L}$ & $101.3(78.8-160.3)$ & $88.5(65.3-109.0)$ & $86.4(73.0-110.0)$ & $145.9(88.7-235.8)$ & 0.002 \\
\hline $\mathrm{CRP}, \mathrm{mg} / \mathrm{L}$ & $3.2(1.4-6.9)$ & $1.1(0-2.6)$ & $3.3(1.8-7.2)$ & $5.5(1.5-7.8)$ & 0.031 \\
\hline$S, \%$ & $13.0(5.5-22.2)$ & $11.5(8.3-14.5)$ & $10.5(5.5-22.2)$ & $14.0(2.5-33.3)$ & 0.912 \\
\hline SS/NS, \% & $15.5(8.3-24.8)$ & $14.5(10.8-23.8)$ & $11.0(7.0-21.5)$ & $19.5(10.0-29.0)$ & 0.159 \\
\hline Total sclerosis, \% & $15.8(10.8-23.4)$ & $14(10.4-18.4)$ & $14.3(6.8-21.1)$ & $16.8(13.9-27.4)$ & 0.088 \\
\hline RTa/RIf & $1.7 \pm 0.6$ & $1.4 \pm 0.5$ & $1.4 \pm 0.6$ & $2.0 \pm 0.5$ & 0.000 \\
\hline
\end{tabular}

Data are presented as $n(\%)$, mean $\pm \mathrm{SD}$, or median (25th-75th percentile). UTP, urine total protein; Alb, albumin; Scr, serum creatinine; eGFR, estimated glomerular filtration rate; CRP, C-reactive protein; S, global sclerosis in glomeruli; SS/NS, segmental or nodular sclerosis in glomeruli; RTa/RIf, renal tubular atrophy/renal interstitial fibrosis ratio.

a Compares Alport FSGS, obesity-related FSGS, and diabetic nephrology groups.

Table 2. Plasma and urinary suPAR levels in patients and controls

\begin{tabular}{lcc}
\hline Diseases & Plasma suPAR level, pg/mL & Urinary suPAR level, pg/ $\mu$ mol \\
\hline Secondary FSGS & $3,317.3(2,738-4,496.2)$ & $336(178.5-456.2)$ \\
$\quad$ Alport-FSGS & $3,671.7(2,654.9-4,555.3)$ & $224.8 \pm 111.7^{\mathrm{a}}$ \\
Obesity-related FSGS & $3,213.4(2,677.9-4,186.5)$ & $322.9(179.7-420.6)$ \\
Diabetic nephropathy & $3,663.6(2,818-4,580.6)$ & $347.9(206.9-621.7)$ \\
Primary FSGS & $2,923(2,205.2-4,359.6)$ & $500.6(262.8-1,059.4)$ \\
Minimal change disease & $2,050(1,813-2,249)$ & $307.9(216.5-480.2)$ \\
Membranous nephropathy & $2,028(1,512-2,715)$ & $250.2(170.4-357.6)$ \\
Healthy control & $1,739.4(1,575.6-2,063.3)$ & $183.6(103.9-228.8)$ \\
\hline
\end{tabular}

Data are presented as the median (25th-75th percentile).

a Only 2 urine samples were obtained from 2 obesity-related FSGS patients.

distributed variables or 1 normally and 1 nonnormally distributed variable. Spearman's correlation test was used to measure the correlation between 2 nonnormally distributed variables or 1 normally and 1 nonnormally distributed variable. All statistical analyses were two-tailed and $p<0.05$ was considered statistically significant.

\section{Results}

\section{Demographic and Clinical Characteristics}

The detailed data are shown in Table 1. The average age was $38.3 \pm 15.7$ years, similar to the healthy controls. AlportFSGS patients were younger while those with diabetic nephropathy were older. There were more men than women in our cohort study. Patients were mainly had less than chronic kidney disease (CKD) stage 3 (estimated glomerular filtration rate [eGFR] 75.5 [IQR 43.0-100.6] mL/ $\left.\mathrm{min} / 1.73 \mathrm{~m}^{2}\right)$. Their median urine total protein was $4.2(2.5-$ 5.9) $\mathrm{g} / 24 \mathrm{~h}$. The mean serum albumin was $33.0 \pm 6.2 \mathrm{~g} / \mathrm{L}$. The median serum creatinine was 101.3 (78.8-160.3) mmol/L.

\section{Plasma and Urinary suPAR Levels}

The suPAR levels of patients with secondary FSGS, primary FSGS, MCD, MN, and healthy subjects are shown in Table 2 and Figure 1. The plasma suPAR level in patients with secondary FSGS (3,317.3 [IQR 2,738-4,496.2] $\mathrm{pg} / \mathrm{mL}$ ) was higher than in patients with primary FSGS (2,923 [IQR 2,205.2-4,359.6] pg/mL, $p=0.042), \mathrm{MCD}$ 


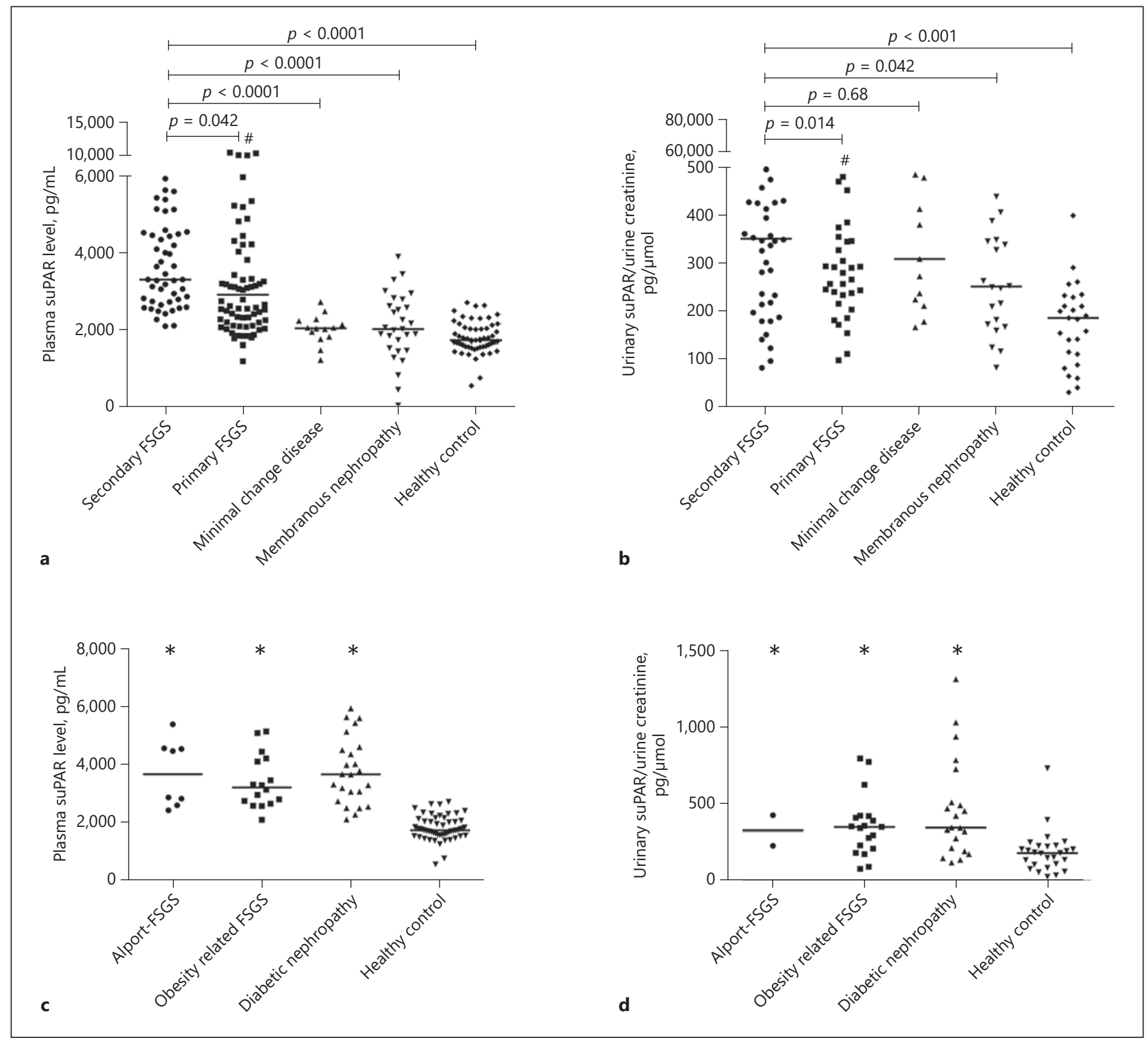

Fig. 1. Plasma and urinary suPAR levels in secondary FSGS patients and controls. a The plasma suPAR levels were increased in both primary and secondary FSGS patients. $\mathbf{b}$ The urinary suPAR levels were increased in both primary and secondary FSGS patients. c The plasma suPAR levels were elevated in all 3 secondary FSGS groups, but there was no difference across groups. d The urinary suPAR levels were elevated in all 3 sencondary FSGS groups, but there was no difference across groups. " Plasma and urinary suPAR levels of primary FSGS were higher than that in minimal-change disease, membranous nephropathy, and in healthy controls. * Compared with healthy controls, levels in the 3 subgroups of secondary FSGS were higher.
(2,050 [IQR 1,813-2,249] pg/mL, $p<0.0001), \mathrm{MN}(2,028$, IQR $1,512-2,715 \mathrm{pg} / \mathrm{mL}, p<0.0001)$, and that in healthy controls $(1,739$ [IQR 1,576-2,063] pg/mL, $p<0.0001)$ (Fig. 1a). The urinary suPAR level in patients with secondary FSGS (335.9 [IQR 178.5-456.2] pg/ $\mu \mathrm{moL}$ ) was lower than in patients with primary FSGS (500.6 [IQR $262.8-1,059.4] \mathrm{pg} / \mu \mathrm{moL}, p=0.014)$ and higher than in those with MCD (307.9 [IQR 216.5-480.2] pg/ $\mu \mathrm{moL}, p=$ $0.68), \mathrm{MN}(250.2$ [IQR 170.4-357.6] pg/ $\mu \mathrm{moL}, p=0.042)$, and in healthy controls (183.6 [IQR 103.9-228.8] pg/ 
Fig. 2. Correlation of plasma and urinary suPAR level in secondary FSGS. There was no correlation between the level of plasma and urinary suPAR in all secondary FSGS patients $(p=0.76)$.

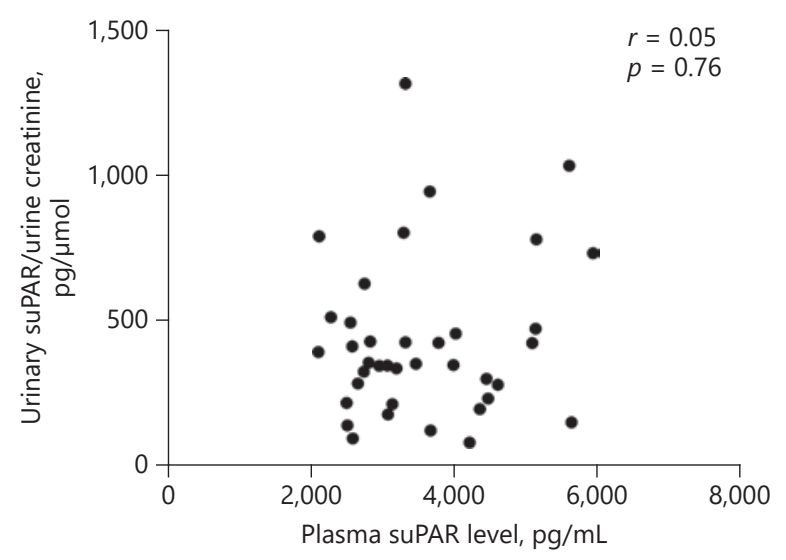

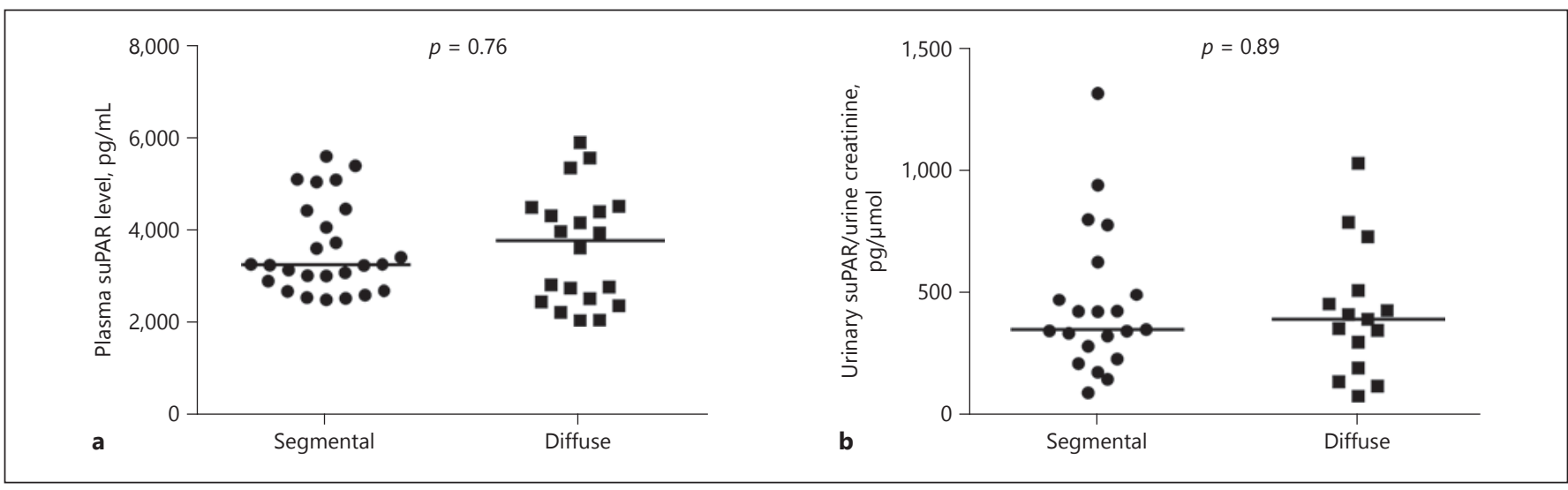

Fig. 3. Plasma and urinary suPAR levels among secondary FSGS patients with different degrees of effacement of foot processes. a There was no significant difference in plasma suPAR levels in the segmental-effacement and diffuse-effacement groups (3,306

$\mu \mathrm{moL}, p<0.001$ ) (Fig. 1b). The plasma and urinary suPAR levels in patients with Alport-FSGS, obesity-related FSGS, and diabetic nephropathy were all notably higher than in the healthy controls, but comparable among themselves ( $p=0.64$ and $p=0.72$, respectively) (Fig. 1c, d). Furthermore, there was no correlation between the levels of plasma and urinary suPAR $(r=0.05, p=0.76$; Fig. 2). We analyzed the relationship between podocyte injury detected by electron microscope and plasma and urinary suPAR levels in secondary FSGS. We found that there was no significant difference in plasma suPAR level in the segmental-effacement group and diffuse-effacement group (3,306 [IQR 2,901-4,479] vs. 3,827.7 [IQR $2,522.8-4,516] \mathrm{pg} / \mathrm{mL}, p=0.76$; Fig. 3a), or in urinary suPAR levels in these 2 groups (352 [IQR 258-561] vs. 393 [IQR 196-513] pg/ $\mu \mathrm{moL}, p=0.89$; Fig. 3b).

suPAR Levels in Secondary FSGS
$[2,901-4,479]$ vs. $3,827.7[2,522.8-4,516] \mathrm{pg} / \mathrm{mL}, p=0.76)$. b There was also no significant difference in urinary suPAR levels in the segmental-effacement and diffuse-effacement groups (352 [258$561]$ vs. 393 [196-513] pg/ $\mu \mathrm{moL}, p=0.89)$.

\section{Associations between suPAR Levels and Clinical and} Pathological Data of Patients with Secondary FSGS

Overall, plasma and urinary suPAR levels did not correlate with any of our clinical and pathological data, including albumin, serum creatinine, eGFR, urine total protein, C-reactive protein (CRP), and glomerular global sclerosis or segmental sclerosis (Table 3 ). When we analyzed the correlation in the Alport-FSGS, obesity-related FSGS, and diabetic nephropathy groups, respectively, we found that only plasma suPAR level was negatively correlated with serum albumin in obesity-related FSGS $(r=-0.73, p=0.0013$; Table 4$)$. The plasma suPAR level was higher in half of the patients with a higher proportion of glomerular global sclerosis $(3,669.3$ [IQR $3,129.4-4,583.4$ ] vs. $2,952.6$ [IQR 2,551.6-4,211.9] pg/ $\mathrm{mL}, p=0.42$; Table 5). 
Table 3. Correlations between plasma suPAR level and clinical and pathological parameters in patients with secondary FSGS

\begin{tabular}{|c|c|c|c|c|}
\hline & \multicolumn{2}{|c|}{ Plasma suPAR level, pg/mL } & \multicolumn{2}{|c|}{ Urinary suPAR level, pg/ $\mu \mathrm{mol}$} \\
\hline & $r$ & $p$ & $r$ & $p$ \\
\hline UTP, g/24 h & -0.043 & 0.77 & -0.00032 & 0.99 \\
\hline Alb, g/L & -0.12 & 0.40 & -0.15 & 0.33 \\
\hline $\mathrm{Scr}, \mathrm{mmol} / \mathrm{L}$ & 0.025 & 0.87 & -0.046 & 0.77 \\
\hline \multicolumn{5}{|l|}{ Pathological parameters } \\
\hline $\mathrm{S}, \%$ & 0.15 & 0.32 & -0.024 & 0.88 \\
\hline SS/NS, \% & -0.22 & 0.14 & 0.21 & 0.18 \\
\hline Total sclerosis, $\%$ & -0.11 & 0.44 & 0.15 & 0.33 \\
\hline $\mathrm{RTa} / \mathrm{RIf}$ & 0.18 & 0.21 & 0.12 & 0.47 \\
\hline
\end{tabular}

UTP, urine total protein; Alb, albumin; Scr, serum creatinine; eGFR, estimated glomerular filtration rate; CRP, C-reactive protein; $\mathrm{S}$, global sclerosis in glomeruli; SS/NS, segmental or nodular sclerosis in glomeruli; RTa/RIf, renal tubular atrophy/renal interstitial fibrosis ratio.

Table 4. Correlation between the level of plasma suPAR and clinical parameters in patients with Alport-FSGS, obesity-related FSGS, and diabetic nephropathy

\begin{tabular}{|c|c|c|c|c|c|c|}
\hline \multirow[t]{2}{*}{ Clinical parameters } & \multicolumn{2}{|c|}{ Alport-FSGS $(n=8)$} & \multicolumn{2}{|c|}{ Obesity-related FSGS $(n=16)$} & \multicolumn{2}{|c|}{ Diabetic nephropathy $(n=24)$} \\
\hline & $r$ & $p$ & $r$ & $p$ & $r$ & $p$ \\
\hline UTP, g/24 h & 0.36 & 0.39 & 0.28 & 0.29 & -0.34 & 0.11 \\
\hline $\mathrm{Alb}, \mathrm{g} / \mathrm{L}$ & -0.40 & 0.33 & -0.73 & 0.0013 & 0.26 & 0.22 \\
\hline $\mathrm{Scr}, \mathrm{mmol} / \mathrm{L}$ & 0.19 & 0.66 & -0.21 & 0.44 & 0.17 & 0.44 \\
\hline $\mathrm{eGFR}, \mathrm{mL} / \mathrm{min} / 1.73 / \mathrm{m}^{2}$ & -0.38 & 0.36 & -0.15 & 0.57 & -0.21 & 0.31 \\
\hline $\mathrm{CRP}, \mathrm{mg} / \mathrm{L}$ & -0.44 & 0.30 & -0.34 & 0.29 & 0.01 & 0.98 \\
\hline
\end{tabular}

UTP, urine total protein; Alb, albumin; Scr, serum creatinine; eGFR, estimated glomerular filtration rate; CRP, C-reactive protein.

\section{Discussion}

In recent years, the discovery of suPAR as a major circulating permeability factor for the pathogenesis of human primary FSGS has been met with great enthusiasm. Many reports examining the original findings of Wei et al. [8] have supplied evidence to either challenge or support them. Supposing that suPAR were the major culprit causing primary FSGS, its concentration in plasma should then be different from that in secondary FSGS, i.e., FSGS caused by other mechanisms. We designed a study that enrolled patients with the 3 most-common types of secondary FSGS or podocytopathy: FSGS caused by obesity, Alport-FSGS, and diabetic nephropathy. But, to our surprise, the plasma and urinary suPAR levels in these 3 groups were all higher than in healthy controls. The plasma suPAR level was even a little higher than in primary FSGS while the urinary suPAR level was lower (with statistical significance, $p<0.05$ ).

As the molecular weight of suPAR fragments ranges from 22 to $45 \mathrm{kDa}$, some experts have raised the point that these molecules could pass through the glomerular filtration barrier, so a higher level of plasma suPAR may be closely related with a lower eGFR. A case in point was when Spinale et al. [15] found that the serum suPAR concentration inversely correlated with the eGFR. Other research supports this observation [16-18]. In our previous work, plasma suPAR of patients with primary FSGS was indeed mildly negatively correlated with eGFR, but after adjusting for renal function, this level was still significantly higher than that in MCD and MN [9]. 
Table 5. Comparison between different pathological groups in patients with secondary FSGS

\begin{tabular}{|c|c|c|c|}
\hline Parameter & Patients, $n$ & Plasma suPAR level ${ }^{\mathrm{a}}, \mathrm{pg} / \mathrm{mL}$ & $p$ value \\
\hline \multicolumn{4}{|l|}{ S } \\
\hline$<13 \%$ & 23 & $2,952.6(2,551.6-4,211.9)$ & \multirow[t]{2}{*}{0.042} \\
\hline$\geq 13 \%$ & 25 & $3,669.3(3,129.4-4,583.4)$ & \\
\hline \multicolumn{4}{|l|}{ SS/NS } \\
\hline$<15.5 \%$ & 24 & $4,003.1(2,634.8-4,521.6)$ & \multirow[t]{2}{*}{0.42} \\
\hline$\geq 15.5 \%$ & 24 & $3,163.6(2,752.3-4,323.3)$ & \\
\hline \multicolumn{4}{|l|}{$\mathrm{RTa} / \mathrm{RIf}$} \\
\hline 1 & 18 & $3,100.9(2,695.0-4,487.8)$ & \multirow[t]{2}{*}{0.48} \\
\hline 2 & 30 & $3,391.2(2,766.7-4,530.0)$ & \\
\hline \multicolumn{4}{|c|}{ Total sclerosis } \\
\hline$<16 \%$ & 23 & $4,211.9(2,597.5-5,088.4)$ & \multirow[t]{2}{*}{0.20} \\
\hline$\geq 16 \%$ & 25 & $3,291.7(2,769.5-3,882.7)$ & \\
\hline
\end{tabular}

S, global sclerosis in glomeruli; SS/NS, segmental or nodular sclerosis in glomeruli; RTa/RIf, renal tubular atrophy/renal interstitial fibrosis ratio.

a Median (25th-75th percentile).

In this study, we did not find any correlation between plasma suPAR and eGFR, although we cannot exclude this possibility as our study had the limitation of a small sample size. Furthermore, the plasma suPAR level in obesity-related FSGS and Alport-FSGS patients was still notably elevated, even though their eGFR $(89.5 \pm 32.2$ and $103.8 \pm 32.7$ $\mathrm{mL} / \mathrm{min} / 1.73 \mathrm{~m}^{2}$, respectively; Table 1) was higher. Finally, no correlation between plasma and urinary suPAR levels was found. These results suggest that the elevated suPAR level in FSGS cannot be attributed only to decreased eGFR but may also be linked to disease entities/podocytopathies, whether primary or secondary. It is already known that plasma suPAR levels in critically ill patients resulting from nonrenal causes are notably elevated, such as in patients with systemic inflammation, cancer, etc. [19-21]. In this study, none of our patients had elevated CRP, a sensitive biomarker of inflammatory status, and the suPAR levels also did not correlate with CRP, indicating that their high suPAR levels were not caused by systemic inflammation either. Nevertheless, elevation of plasma suPAR may be related to FSGS associated podocytopathies, for almost no such report in patients with MCD or MN.

In this present study, as found in patients with primary FSGS, the level of plasma suPAR notably increased in all 3 types of secondary FSGS but it had no correlation with urine protein. This result might suggest that suPAR is not a circulating permeability factor as has been reported in several studies [15-17, 22, 23]. We found a negative correlation between plasma suPAR level and serum albumin in obesity- related FSGS, but we cannot provide a rational explanation for this. Overall, a high level of plasma suPAR might participate in the pathogenesis of FSGS-associated podocytopathy, or else it is only a biomarker of podocyte injury. Recently, Hayek et al. [24] found that elevated baseline plasma suPAR levels were independently associated with impending CKD and a more rapid decline in eGFR in individuals with normal kidney function. Our results showed that the plasma suPAR level was higher in half of the patients with a higher proportion of glomerular global sclerosis, which also supports the finding of Hayek et al. [24].

Compared with patients with primary FSGS, the patients with secondary FSGS in our study had higher plasma suPAR levels and lower urinary suPAR levels, but these values could not be used as tools to distinguish primary FSGS from secondary FSGS since there was a large overlap between these 2 groups in the scatter diagram.

In conclusion, the levels of plasma suPAR in patients with Alport-FSGS, obesity-related FSGS, and diabetic nephropathy were increased. Plasma suPAR might be an important pathogenetic factor or a useful marker of glomerular diseases with various podocytopathies, but not necessarily a circulating permeability factor.

\section{Acknowledgment}

This study was supported by a grant from the National Natural Science Foundation of China (no. 81370809). 


\section{Statement of Ethics}

Informed consent was obtained from each patient, and the design of our work was in keeping with the Declaration of Helsinki and approved by the local clinical research ethics committee of Peking University First Hospital.

\section{Disclosure Statement}

The authors have no conflicts of interest to declare.

\section{Author Contributions}

$\mathrm{PpS}$ carried out the conception and design of this study and the collection, analysis, and interpretation of data, and drafted the manuscript. LY helped collection the data of patients. JH provided technical assistance. SxW and WzZ offered powerful support in pathology. LY raised good suggestions during the study and revised the manuscript. GL carried out the conception and design of the study and the renal pathological analysis, and also revised the manuscript.

\section{References}

1 Kitiyakara C, Eggers P, Kopp JB. Twenty-oneyear trend in ESRD due to focal segmental glomerulosclerosis in the United States. Am J Kidney Dis. 2004 Nov;44(5):815-25.

2 Ponticelli C, Glassock RJ. Posttransplant recurrence of primary glomerulonephritis. Clin J Am Soc Nephrol. 2010 Dec;5(12):2363-72.

3 Hoyer JR, Vernier RL, Najarian JS, Raij L, Simmons RL, Michael AF. Recurrence of idiopathic nephrotic syndrome after renal transplantation. 1972. J Am Soc Nephrol. 2001 Sep;12(9):1994-2002.

4 Haas M, Godfrin Y, Oberbauer R, Yilmaz N, Borchhardt K, Regele H, et al. Plasma immunadsorption treatment in patients with primary focal and segmental glomerulosclerosis. Nephrol Dial Transplant. 1998 Aug;13(8): 2013-6.

5 Artero ML, Sharma R, Savin VJ, Vincenti F. Plasmapheresis reduces proteinuria and serum capacity to injure glomeruli in patients with recurrent focal glomerulosclerosis. Am J Kidney Dis. 1994 Apr;23(4):574-81.

6 Kemper MJ, Wei C, Reiser J. Transmission of glomerular permeability factor soluble urokinase plasminogen activator receptor (suPAR) from a mother to child. Am J Kidney Dis. 2013 Feb;61(2):352.

7 Kemper MJ, Wolf G, Müller-Wiefel DE. Transmission of glomerular permeability factor from a mother to her child. N Engl J Med. $2001 \mathrm{Feb} ; 344(5): 386-7$

8 Wei C, El Hindi S, Li J, Fornoni A, Goes N, Sageshima J, et al. Circulating urokinase receptor as a cause of focal segmental glomerulosclerosis. Nat Med. 2011 Jul;17(8):952-60.

9 Huang J, Liu G, Zhang YM, Cui Z, Wang F, Liu XJ, et al. Plasma soluble urokinase recep- tor levels are increased but do not distinguish primary from secondary focal segmental glomerulosclerosis. Kidney Int. 2013 Aug;84(2): 366-72.

10 Savige J, Sheth S, Leys A, Nicholson A, Mack HG, Colville D. Ocular features in Alport syndrome: pathogenesis and clinical significance. Clin J Am Soc Nephrol. 2015 Apr;10(4):7039.

11 Darouich S, Goucha R, Jaafoura MH, Zekri S, Ben Maiz H, Kheder A. Clinicopathological characteristics of obesity-associated focal segmental glomerulosclerosis. Ultrastruct Pathol. 2011 Aug;35(4):176-82.

12 Raparia K, Usman I, Kanwar YS. Renal morphologic lesions reminiscent of diabetic nephropathy. Arch Pathol Lab Med. 2013 Mar; 137(3):351-9.

13 Najafian B, Alpers CE, Fogo AB. Pathology of human diabetic nephropathy. Contrib Nephrol. 2011;170:36-47.

14 Charles Jennette J, Olson JL, Silva FG, D’Agati VD, editors. Heptinstall's Pathology of the Kidney. 7th ed. Alphen aan den Rijn: Wolters Kluwer; 2014.

15 Spinale JM, Mariani LH, Kapoor S, Zhang J, Weyant R, Song PX, et al; Nephrotic Syndrome Study Network. A reassessment of soluble urokinase-type plasminogen activator receptor in glomerular disease. Kidney Int. 2015 Mar;87(3):564-74.

16 Meijers B, Maas RJ, Sprangers B, Claes K, Poesen R, Bammens B, et al. The soluble urokinase receptor is not a clinical marker for focal segmental glomerulosclerosis. Kidney Int. 2014 Mar;85(3):636-40.

17 Wada T, Nangaku M, Maruyama S, Imai E, Shoji K, Kato S, et al. A multicenter cross-sec- tional study of circulating soluble urokinase receptor in Japanese patients with glomerular disease. Kidney Int. 2014 Mar;85(3):641-8.

18 Sinha A, Bajpai J, Saini S, Bhatia D, Gupta A, Puraswani M, et al. Serum-soluble urokinase receptor levels do not distinguish focal segmental glomerulosclerosis from other causes of nephrotic syndrome in children. Kidney Int. 2014 Mar;85(3):649-58.

19 Slot O, Brünner N, Locht H, Oxholm P, Stephens RW. Soluble urokinase plasminogen activator receptor in plasma of patients with inflammatory rheumatic disorders: increased concentrations in rheumatoid arthritis. Ann Rheum Dis. 1999 Aug;58(8):488-92.

20 Yilmaz G, Köksal I, Karahan SC, Mentese A. The diagnostic and prognostic significance of soluble urokinase plasminogen activator receptor in systemic inflammatory response syndrome. Clin Biochem. 2011 Oct;44(1415):1227-30.

21 Mazar AP, Henkin J, Goldfarb RH. The urokinase plasminogen activator system in cancer: implications for tumor angiogenesis and metastasis. Angiogenesis. 1999;3(1):15-32.

22 Bock ME, Price HE, Gallon L, Langman CB. Serum soluble urokinase-type plasminogen activator receptor levels and idiopathic FSGS in children: a single-center report. Clin J Am Soc Nephrol. 2013 Aug;8(8):1304-11.

23 Eugen-Olsen J, Giamarellos-Bourboulis EJ. suPAR: the unspecific marker for disease presence, severity and prognosis. Int J Antimicrob Agents. 2015 Dec;46 Suppl 1:S33-4.

24 Hayek SS, Sever S, Ko YA, Trachtman H, Awad M, Wadhwani S, et al. Soluble Urokinase Receptor and Chronic Kidney Disease. N Engl J Med. 2015 Nov;373(20):1916-25. 